\title{
i
}

\section{Fausto da Longiano e a tradução retórica do século XVI Mauri Furlan}

RESUMO: Dialogo del modo de lo tradurre, 1556, de Sebastiano Fausto da Longiano, é o primeiro tratado independente escrito em italiano sobre a tradução, e um dos mais significativos do Renascimento europeu. Nele, além das principais posiçōes mantidas nas disputas sobre a tradução no período, também se encontram preceitos constituidores da grande linha de pensamento que caracterizou a reflexāo sobre a tradução renascentista e que chamamos de "teoria retórico-locuriva da tradução": o código que plasma a concepção da linguagem no Renascimento e, conseqüentemente, o código da tradução é o da elocutio retórica.

PALAVRAS-CHAVE: teoria da tradução; Renascimento; retórica; Fausto da Longiano.

Sebastiano Fausto Da Longiano (ca. 1500 - ca. 1560), autor com certa fama e prestígio em seu tempo, incluído pela crítica italiana entre os "poligraf" ou "avventurieri della penna" - ou seja, escritores de prosa em língua italiana, freqüentemente de origem humilde (Guthmüller 1991: 23) - atualmente quase não é mencionado na história da literatura italiana. Tampouco é muito conhecido na história da traduçāo, e as escassas menções neste tipo de obras (Norton, Ideology, 1984, e Rener, Interpretatio, 1989) contêm equívocos de interpretaçáo do texto faustino. No entanto, a obra de Longiano Dialogo del modo de lo tradurre, publicada em Veneza em 1556, é o primeiro tratado independente escrito em italiano sobre a tradução. É um texto-chave para a história da teoria da traduçáo no Renascimento porque se insere no conjunto de reflexōes que contribuem para a constituição de uma história da teoria da tradução no período, como traduçáo retórica. Para Norton, é "the most thorough Renaissance treatise on translation prior to Lawrence Humphrey's 
Interpretatio Linguarum" (Norton 1984: 198). Nele também se refletem as principais posiçóes mantidas nas disputas sobre a tradução por volta da metade do Cinquecento. O Dialogo tenta pela primera vez, segundo Bodo Guthmüller,

dare una definizione del tradurre, distinguendo il genere della traduzione da quelle altre forme di ricezione del testo che venivano ancora considerate come traduzione (la metafrasi, la parafrasi, l'ispianatione, il compendio, Pillustratione). (1991: 10)

Diante do crescimento do vulgar no Cinquecento, criticava-se - sobretudo por parte dos humanistas - o uso de traduçóes. Temia-se que, pelo viés da tradução, se desse um empobrecimento da educação clássica e a decadência da cultura literária latina: as traduçôes reduziriam o interesse pelas línguas antigas e não poderiam reproduzir a precisão conceitual e a magnitude dos textos clássicos. Guthmüller chama a atenção para o fato de que os próprios humanistas que recusam a tradução para o vulgar são os literatos que tentam elevar a língua e a literatura italianas à dignidade do latim, e por isso são também chamados humanistas do vulgar: Bembo, Castiglione, Ariosto. A explicação que oferece o investigador alemão para a posição subalterna da tradução no vulgar, num momento em que a língua italiana começa a afirmarse paritariamente ou inclusive superiormente à latina, é a de "uma necessidade da vanguarda humanista do vulgar" (1998: 23). A posição de Bembo é um exemplo válido para a maioria dos escritores de seu tempo: Bembo queria dar ao vernacular a mesma capacidade de expressão do latim por meio de uma rigorosa regulamentação. Os meios para esta regulamentação deveriam ser adequados à estrutura da língua moderna e serem derivados da tradição da língua popular, cujo modelo eram sobretudo Petrarca e Boccaccio. A tradução do latim representava um perigo, pois poderia facilmente assimilar elementos estrangeiros. Por isso não é a tradução, mas a imitaçáo que se torna favorita no primeiro humanismo vulgar (Guthmüller 1998).

Na segunda fase do humanismo vulgar, os humanistas têm por objetivo a difusão da língua italiana e defendem a prática da tradução das línguas clássicas "convinti di poter emulare gli originali latini e perfino di superarli con i mezzi della propria lingua e letteratura" (Guthmüller 1991: 17). Por volta de 1550, comenta o pesqui- 
sador alemão, o problema básico, se é lícito traduzir ou não, perde importância para a questão de como traduzir. Revelador desta nova posição é o título do tratado de Fausto, Dialogo del modo de lo tradurre. Retoma-se a velha controvérsia de se se deve traduzir secondo le parole o secondo il senso. Quase sempre os literatos se declaram a favor do segundo modo e alguns propóem um caminho intermediário, sendo Cícero o grande ponto de referência e discussão. No entanto, enquanto para alguns o autor latino legitima a tradução livre, para outros, o orador não tratou da tradução, mas da imitação. "Intorno al 1540", relata Guthmüller,

erano presenti in Italia le premesse culturali, letterarie e linguistiche per lo sviluppo di una prassi di traduzione assai libera. [...] Intorno al 1560 si avvertono nella letteratura italiana nuove tendenze; dopo un periodo di rigogliosa crescita si sente il bisogno di classificare e di sistemare. La critica letteraria, la filologia, le poetiche acquistano terreno, il volgare si avvicina di nuovo alla tradizione classica. La teoria normativa di Fausto sembra un precoce riflesso di queste nuove tendenze critiche e dogmatiche che domineranno la storia della letteratura italiana e apriranno la strada al classicismo. (1991: 53)

Homem da corte, literato erudito, tratadista, ensaísta, editor, Fausto também traduziu vários textos gregos e latinos (Aristóteles, Dioscórides, Cícero, Erasmo, papa Pio II), entre os quais as traduçóes de Cícero merecem maior interesse, tanto por seu autor, considerado modelo insuperável de língua e estilo, como pelas idéias sobre o modo de traduzir, que vão influenciar este tratado sobre o tema. No Cinquecento, Cícero é de fato também uma autoridade incontestável da teoria da tradução "e i criteri usati per la traduzione delle sue opere avranno carattere normativo per gli altri autori" (Guthmüller 1991: 33). A traduçāo faustina das Epistole dette le familiari di M. T. Cicerone recate in italiano, con le ragioni del modo tenuto ne la tradottione, publicada em 1544, constitui a primeira tradução para o italiano desta obra de Cícero. Apenas um ano depois de sua aparição, Guido Loglio da Reggio publica "una nuova traduzione della stessa opera, accompagnata anch'essa da una prefazione teorica in cui sono dichiarati principi diametralmente opposti a quelli sostenuti da Fausto" (Guthmüller 1991: 32), que pretendia ser uma resposta polêmica à traduçáo anterior. A contestação definitiva de Fausto à tradução e à premissa teórica de Guido Loglio constitui o contexto imediato do Dialogo del modo de lo tradurre. Nele, as 
posições de Loglio são discutidas e condenadas e sua técnica de traduzir é analisada e rebatida. O contraste entre as duas posiçōes antitéticas sobre o modo de traduzir presentes no tratado faustino é representativo do debate da época sobre a questão. Antes da publicaçáo do Dialogo, Fausto havia exposto suas idéias sobre a tradução em dois longos prefácios, um à traduçáo das Epistole familiari de Cícero, em 1544, e outro à traduçáo dos Apoftemmi de Erasmo, em 1546. No Dialogo,

sviluppa e precisa ulteriormente le sue posizioni facendo però ricorso a molte delle idee già esposte nelle due prefazioni, che accoglie in parte testualmente, in parte leggermente modificate nel nuovo trattato. (Guthmüller 1991: 135)

O Dialogo faustino não constitui uma verdadeira discussão, mas antes um questionário, em que os dois protagonistas dialogam a base de perguntas e respostas; um personagem ensina e outro aprende: Inquieto, um espírito que busca a verdade, faz as perguntas a Oculto, um espírito que penetra nas coisas e as revela argumentando. Inquieto apresenta também as opiniōes contrárias às de Oculto, mas não as defende; o ponto de vista correto é o de Oculto, que atua como portavoz do autor.

Fausto apresenta, assim, sua concepção da correta tradução, nomeada ut interpres, que não é senão a tradução que tenta reproduzir, além do sentido, o estilo do original em todos os casos em que o permita a língua de chegada, mantendo-se o mais próximo possivel daquele também no número das palavras, respeitando, contudo, a proprietas de cada uma das línguas. Fausto quer que a tradução reflita o modo de expressão característico do autor traduzido, explorando as possibilidades da língua de chegada até o limite extremo da compreensibilidade.

Estrutura e conteúdo do texto

Informa-nos B. Guthmüller que a primeira ediçáo do Dialogo del modo de lo tradurre, publicado em Veneza em 1556, continha 56 páginas num formato de ca. $15 \times 10 \mathrm{~cm}$. A ediçáo sobre a qual trabalhamos consta de 75 páginas. É uma ediçáo crítica e comentada pelo pesquisador alemáo, precedida de um ensaio seu, Fausto 
da Longiano e il problema del tradurre, publicados na revista Quaderni Veneti, de Ravenna, em 1991.

Pode-se perceber já no título empregado por Fausto da Longiano para seu tratado, Dialogo del modo de lo tradurre d'una in altra lingua segondo le regole mostrate da Cicerone - que lembra o título do breve escrito de Étienne Dolet, La manière de bien traduire d'une langue en autre -, a forma literária (o diálogo) e a linha principal de sua reflexão, ou seja, a discussão sobre a questão da tradução orientada em torno ao pensamento ciceroniano do traduzir. $\mathrm{Na}$ dedicatória aos Academici Costanti, que patrocinavam seu trabalho, Fausto adverte que, por meio de seu tratado, não quis prescrever um modo de traduzir, mas simplesmente mostrar qual havia sido o procedimento em sua prática de tradutor (Longiano 1991: 57). Um esquema possível do Dialogo é sua divisão em nove partes.

I.

Os primeiros parágrafos do tratado ( $\$ \$ 1$ 1-14) são dedicados à exposição da questão central, que retoma o velho problema teórico da traduçáo: deve-se ser fiel às palavras ou ao pensamento contido no texto a traduzir? Um dilema que fora colocado na Antigüidade por Cícero (segundo pesquisadores da linha de G. Mounin, por exemplo, mas uma opinião com a qual não compartilha Fausto da Longiano) e que no Renascimento italiano se apóia nas reflexōes do orador romano sobre a tradução como argumento de defesa tanto de uma como de outra posição. Também se apresenta a hipótese de uma síntese para este dilema, ou seja, a tradução que contempla um caminho intermediário. Fausto tentará refutar estas concepçōes de traduçáo, oferecendo ao mesmo tempo sua concepçáo tradutora e uma nova leitura do pensamento ciceroniano sobre a tradução. O programa básico do Dialogo é tratado abordando várias questōes secundárias que vão se sucedendo.

II.

Já superada parece para Fausto a questão sobre a utilidade e a necessidade da tradução, mas, sem a desmerecer, recoloca-a, contesta e avança em sua reflexão ( $\$ \$$ 
15-37). É óbvia sua necessidade, uma vez considerada a grande quantidade de línguas existentes no mundo e a impossibilidade de o homem conhecer a todas; ainda que fosse apenas das mais importantes (hebraico, caldeu, árabe, grego e latim), já se comprovou ser inviável seu conhecimento para a maioria da populaçáo de uma mesma nação. A utilidade concerne sobretudo à saúde da alma e do corpo do homem, porque a medicina, a Bíblia e demais ciências e artes, as quais são fundamentais para todos, não foram escritas numa mesma língua, mas em várias e distintas. De forma que o conhecimento depende da traduçáo. É necessário traduzir "per l'utilità e per beneficio commune" $(\$ 20)$. Contudo, pode-se questionar a qualidade e proveito aportados pelas traduçōes, que podem ser boas ou ruins. É neste momento que Fausto, na voz de Oculto e Inquieto, apresenta uma definição da traduçáo que compreende o conhecimento das línguas e da ciência ou assunto:

OCC.: Può essere che qualche indotto e inetto o per ignoranza de le lingue o de la facoltà commeta errori. Ma che? Non si può dire tradottione quella di colui che traduce ciò che meno intende, ancorché cognitione havesse intiera e perfetta de le lingue. [...]

INQ.: [...] io dico de le tradottioni di coloro che sono in maggiore stima d'intendere le lingue e le scienze. (Fausto da Longiano 1991: \$36)

OC.: Pode ser que algum inculto e inepto ou por desconhecimento das línguas ou da matéria cometa equívocos. E entāo? Não se pode chamar de traduçăo aquela de quem traduz o que não entende, ainda que tivesse conhecimento total e perfeito das línguas. [...]

INQ.: [...] falo das traduçôes daqueles que possuem grande capacidade de entender as línguas e as ciências.

Os tradutores aos quais falta conhecimento nas línguas ou na ciência e que, por isso, cometem inúmeros erros, náo merecem ser chamados convertitori mas sovertitori (conversor/subversor), diz Oculto $(\$ 36)$, num jogo de palavras que alude claramente ao binomio traduttore/traditore.

III.

Mais importante do que a discussão sobre a utilidade da tradução é o como, o modo de lo tradurre. Depois destas primeiras consideraçōes gerais, Fausto, ou Ocul- 
to, se propóe aprofundar a questão da traduçáo, partindo, a exemplo da tradição filosófica, retórica e literária, de uma definiçăo, ainda que negativa, mais precisa, estrita, da traduçáo, diferenciando-a de alguns procedimentos análogos a ela, como a metáfrase, a paráfrase, o compêndio e a explanaçăo (\$\$2-54).

A metáfrase é definida por Fausto como o recurso de referir o sentido do texto original sem deter-se rigorosamente nas palavras, amplificando, reduzindo, confundindo, transpondo, ensombreando ou transformando o autor principal. A paráfrase consiste em esclarecer o sentido ambíguo ou obscuro do texto original com circunvoluçōes mais longas, porém sempre encadeadas a ele, como numa peleja com o autor. $\mathrm{O}$ compêndio ou epítome é um resumo do sentido compreendido. A explanaçāo, também chamada interpretaçāo, exposição, comentário, narração e explicação, destina-se a explicar o sentido, manifestar os segredos da arte, resolver as contradiçóes, esclarecer as ambigüidades, divulgar a história e as palavras ocultas, mostrar o significado e valor das palavras, apontar as causas e encontrar suas origens, observar a elocução e as locuçôes. Todos estes procedimentos podem realizar-se na mesma língua, ou em língua estrangeira. A tradução, por sua vez, é um procedimento de recepçáo de texto que não se pode produzir senão entre duas línguas distintas. Esta,

per altro nome puossi chiamare interpretatione, conversione, traportatione, traslatione e simili. Ma avertite che gli antichi latini e di miglior nome l'hanno per uso più frequente detta interpretatione e lo tradottore chiamato interprete. (Fausto da Longiano 1991: \$54)

com outro nome pode chamar-se interpretaçăo, conversāo, transportaçăo, traslaçáo e similares. Atentese porém que os antigos latinos e de melhor nome a chamaram mais freqüentemente interpretação $e$ ao tradutor the chamaram intérprete.

A concepçáo faustina de tradução, apresentada e defendida mais adiante em seu Dialogo, como tradução ut interpres, na nomenclatura ciceroniana, é distinta da tradução literal na forma como compreendem seus opositores, entāo representados por Guido Loglio, para quem os tradutores submissos ao significado literal tentam 
esconder seu pouco conhecimento da língua e do argumento do texto a traduzir. Fausto se oporá energicamente às opiniōes de Loglio de “ilustrar" a tradução (\$314), ponendo più cura a la sostanza che a le parole $(\$ 322)$, "cuidando mais da substância que das palavras", transformando o estilo original em estilo da língua de chegada, naturalizando o texto estrangeiro de forma que o leitor leia a obra como se fosse da literatura nacional.

\section{IV.}

A concepção da prática da tradução sob dois modos distintos e opostos, isto é, um que representa o sentido e outro as palavras, ou a escolha de um caminho intermediário, é rechaçada por Fausto $(\$ \$ 55-56$ ) por estar a questão mal colocada e por ele considerá-la "falsa" (non vera) e "defeituosa" (menda), porque

La tradottione che rappresenta le parole, non rappresenta necessariamente le sentenze anchora? (Fausto da Longiano 1991: \$56)

A tradução que representa as palavras não representa necessariamente também as sentenças?

Traduzir não apenas palavra por palavra, mas computar as palavras, como preceptua Cícero ao tradutor-interpres, tem por objetivo representar o sentido ( $\$ 328$ ). Desde a Antigüidade é sabido que as coisas são representadas pelas palavras e, ao traduzir as palavras com propriedade e entendimento, se estará expressando o pensamento convenientemente. Lo tradurre di parola in parola non è cosa nuova né puerile (\$ 59), "traduzir palavra por palavra não é algo novo nem infantil" Assim o fez também Cícero, afirma Fausto, e tenta mostrá-lo com as próprias palavras do romano ( $\$ \$ 57-70)$. Nas Tusculanae disputationes, Cícero fala do "ofício do intérprete", munere interpretis:

... Sunt haec tua verba necne? In eo quidem livro qui continet omnem disciplinam tuam (fungar enim iam interpretis munere, ne quis me putet fingere)... (Tusculanae disputationes, III, XVIII, 31)

... Acaso não são estas tuas palavras? Naquele livro que, por certo, contém toda tua doutrina (vou desempenhar agora a função de intérprete para que não creiam que invento)... 


\section{E mostra ter traduzido como intérprete:}

Haec Epicuro confitenda sunt aut ea quae modo expressa ad verbum dixi tollenda de livro (Tusculanae disputationes, III, XIX, 44). ${ }^{1}$

Epicuro deve reconhecê-las ou tirá-las de seu livro todas estas coisas que traduzi expressamente palavra por palavra.

Itaque istum ego locum toridem verbis a Dicaearcho transtuli. (Epistolae ad Atticum, VI, 2)

Por isso traduzi esta passagem de Dicáiarcos com o mesmo número de palavras.

A alternativa de traduzir segundo a letra ou segundo o sentido não pode ser atribuída a Cícero, que não fala sobre isso em nenhuma de suas obras. De fato, este pensamento é de São Jerônimo, cuja epístola De optimo genere interpretandi não é uma só vez citada por Fausto.

V.

Em De optimo genere oratorum, Cícero diferenciaria dois modos de traduzir, $u t$ interpres e ut orator ( $\$ \$ 71-120$ ). Oculto serve-se do texto de Cícero para explicar as duas formas de traduzir, comparando entre si as seguintes passagens:

Nec conuerti ut interpres, sed ut orator, iisdem sententiis et earum formis tanquam figuris, uerbis ad nostram consuetudinem aptis. In quibus non uerbum pro uerbo necesse habui reddere, sed genus omnium ${ }^{2}$ uerborum uimque seruaui. Non ea enim me adnumerare lectori putaui oportere, sed tanquam appendere (De optimo genere oratorum, V, 14).

Quorum ego orationes si, ut spero, ita expressero uirtutibus utens illorum omnibus, id est sententiis et earum figuris et rerum ordine, uerba persequens eatenus ut ea non abhorreant

1. A crítica moderna considera a traduçāo ciceroniana de Epicuro uma exceçāo em seu modo de traduzir, pois, ao traduzir o filósofo grego palavra por palavra, o orador romano tentava refutá-lo com suas próprias palavras, sem nenhuma pretensão literária (Guthmüller 1991: 40).

2. Fausto lê omnium em vez de omne, segundo se encontra na ediçăo de Paolo Manuzio. 
a more nostro (quae si e Graecis omnia conversa non erunt, tamen ut generis eiusdem sint, elaboravimus), erit regula, ad quam eorum dirigantur orationes, qui Attice uolunt dicere (De optimo genere oratorum, VI, 23).

Não traduzi como intérprete, mas como orador, com os mesmos pensamentos e suas formas bem como com suas figuras, com palavras adequadas ao nosso costume. Para tanto náo tive necessidade de traduzir palavra por palavra, mas mantive o gênero das palavras e sua força.

Se, como espero, eu tiver assim reproduzido os discursos dos dois servindo-me de todos seus valores, isto é, com os pensamentos e suas figuras e na ordem das coisas, respeitando suas palavras até o ponto em que elas não se distanciem de nosso uso (as quais se não foram todas traduzidas das gregas, esforçamo-nos contudo para que sejam do mesmo caráter), haverá um modelo ao qual possam se adequar os discursos daqueles que querem falar de modo ático.

Opondo-se à compreensão comum de sua época - e também à da crítica moderna - de que Cícero tenderia a privilegiar a tradução ut orator, que respeita o aspecto estilístico do modelo numa reproduçáo mais livre, e rechaçaria o modo ut interpres, própria do tradutor pedante que, por ignorância lingüística, não consegue desprender-se das palavras do original, Fausto apresenta uma nova leitura do texto ciceroniano. Para o tratadista italiano, Cícero admite ambas as formas, mas aceita com reservas a maneira de traduzir ut orator, considerando, por fim, como o único método correto a tradução ut interpres. E serve-se de muitos exemplos de escritores do passado e do presente que traduziram palavra por palavra. A questão é: o que entende Fausto ao falar de tradução palavra por palavra ou ut interpres?

Interpretando o texto de Cícero, Oculto entende que, como orador, o tradutor se fixa nos pensamentos, usa as mesmas formas e figuras com as palavras adequadas segundo o costume, conservando o caráter e a força de todas as palavras. $\mathrm{O}$ intérprete, por sua vez, além de fazer o mesmo que o orador, deve não apenas verter palavra por palavra, mas necessariamente contar as palavras $(\$ 74)$. No final, conclui Guthmüller,

La differenza tra il "convertere ut interpres" - a cui va il favore di Fausto - e il "convertere ut orator" consiste dunque nel fatto che l'“interpres" persegue con coerenza la riproduzione dello stile dell'originale in tutti i casi in cui la lingua d'arrivo lo permetta, mentre l'"orator', nel suo tentativo di 
riproduzione, ricorre in misura maggiore a equivalenze stilistiche nella lingua di arrivo. Il traduttore fedele al senso, infine (non previsto da Cicerone), tradisce lo stile dell'originale per adeguarsi al gusto del nuovo pubblico. (1991: 41)

Em De optimo genere oratorum, Cícero não estaria defendendo a "tradução como orador" contra a "tradução como intérprete", nem tentando apresentar a primeira como tradução do sentido e a segunda como das palavras. Sua tradução como orador pode ser vista antes como uma exceção a seu modo de traduzir, porque se não tivesse traduzido discursos talvez não tivesse dito que o havia feito ut orator $(\$ 72)$, uma vez que costumava traduzir ut interpres. Ao traduzir os discursos de Demóstenes e Ésquines, o orador romano pretendia dar a conhecer ao público romano os melhores exemplos da oratória ática. Traduzir ut orator não significa uma tradução condicionada somente pelos modos estilísticos da língua de chegada, mas também a consideração do estilo particular do texto original; e se esse tipo de traduçáo, contudo, possui uma maior liberdade que a traduçáo ut interpres, traduzir ut orator não equivale em absoluto a cuidar somente do sentido:

Mirate che non disse Cicerone di voler tradurre semplicemente i sensi, ma disse di voler, oltra lo tradurre i sentimenti, usar le medesime forme e figure con le parole accommodate e servare la vertù de le parole. (Fausto da Longiano 1991: \$75)

Observe que Cícero não disse querer traduzir simplesmente os sentidos, mas disse querer, além de traduzir os entendimentos, usar as mesmas formas e figuras com as palavras adequadas e conservar o valor das palavras.

... iisdem sententiis et earum formis tanquam figuris, verbis ad nostram consuetudinem aptis. [...] Non enim ea me annumerare lectore putaui oportere, sed tanquam appendere. (Cícero, De optimo genere oratorum, $\mathrm{V}, 14$ )

... com os mesmos pensamentos e suas formas bem como com suas figuras, com palavras adequadas ao nosso costume. [...] Não considerei, pois, ser mister enumerá-las ao leitor, mas como que pesá-las. 
1. iisdem sententiis et earum formis tanquam figuris / usar le medesime forme e figure

Deve-se esclarecer, insiste Oculto, que as formas e figuras no texto de Cícero são coisas distintas, que implicam, porém, similitude. Depois de analisar vários autores e escritos do orador ( $\$ \$ 82-90$ ), Oculto conclui que entre os latinos é uma mesma coisa gênero, forma, figura, espécie e caráter $(\$ 88)$, e que Cícero sotto più voci intende una coisa istessa. Lo greco dice schemata; Cicerone forme, ornamenti, lumi, conformationi ( $\$ 90)$, "sob várias vozes entende uma mesma coisa. O grego diz schernata; Cícero, formas, ornamentos, luzes, conformaçōes" Para Cícero - pode-se inferir a partir da comparação entre as passagens do autor citadas acima (nec converti ut interpres, sed ut orator, sententiis iisdem et earum formis tanquam figuris, e, quorum orationes si, ut spero, ita expressero virtutibus utens illorum omnibus, id est sententiis et earum figuris et rerum ordine) -, as formas são a ordem das coisas, entendendo a ordem das coisas como a disposição dos pensamentos ( $\$ \$ 105-106$ ). Manter a forma é, pois, manter a disposição dos pensamentos. Para Cícero, ensina Oculto, eloquentia e oratio são uma mesma coisa, assim como o são res e sententia. Todo discurso consta de coisas e palavras, e estas devem servir a aquelas (\$\$ 115-120). Prima sono i concetti, poi si richieggono le parole da vestirgli ( $\$ 118$ ), "primeiro existem os conceitos, depois as palavras se encarregam de vesti-los". Esta é a base da teoria da linguagem desde a Antigüidade, e um lugar-comum da retórica clássica e humanista. As coisas (res, sententia) não teriam luz sem as palavras, e nem estas, tiradas as coisas, firmeza e estabilidade ( $\$ \$ 115-118$ ). As duas têm sua disposiçáo no discurso:

Sed et verborum est structura quaedam duas res efficiens, numerum et lenitatem. Et sententiae suam compositionem habent, ad probandam rem accommodatum ordinem. (Cícero, De optimo genere oratorum, II, 5)

Mas há uma certa disposiçâo das palavras que produz dois efeitos, ritmo e leveza, e os pensamentos têm sua organização, uma ordem apropriada à demonstração do assunto. 
2. verbis ad nostram consuetudinem aptis / con le parale accommodate

Adaptar as palavras do original ao costume da língua na qual se traduz significa respeitar a proprietas da língua de chegada. Fausto esclarece as palavras de Cícero com um exemplo de tradução do grego ao latim ( $\$$ 108-112) - o início do discurso de Demóstenes contra Ésquines -, em que todas as palavras gregas estão representadas por palavras latinas e, apesar das diferenças gramaticais entre as duas línguas presentes na oração, são respeitadas a morfologia e a sintaxe latinas.

3. sed tanquam appendere / e servare la vertù de le parole

Conservar os valores das palavras na traduçăo é mantê-las significanti, sonore, gravi, piene e numerose (\$113), "significantes, sonoras, graves, plenas e rítmicas", como se encontram no modelo, e, quando isto não pode ser feito, devem ao menos ser similares. Se a conservação do mesmo ritmo não é possível, deve tentar-se a semelhança da composição por meio da aposição, posposição, transposição, comutação e alteração das palavras segundo a língua ( $\$ 113)$. Em suma,

Quelli che vogliono tradurre d'una in altra lingua necessariamente hanno ad isprimere le sentenze, servare l'ordine de le cose, e con le medesime forme e figure, o conformationi, o lumi, od ornamenti, o degnitadi, o schemi che vi piaccia dire. [...] Deggono apresso isplicare le sentenze con parole accommodate e oltra ciò servare la vertù, la forza e 'I valore de le parole di quella lingua da la quale si traporta. (Fausto da Longiano 1991: \$19-120)

Aqueles que querem traduzir de uma língua a outra têm de, necessariamente, expressar as sentenças, conservar a ordem das coisas, e com as mesmas formas e figuras, ou conformaçōes, ou luzes, ou ornamentos, ou esplendores, ou schemae, como prefira chamar. [...] Devem depois explicar as sentenças com palavras adequadas e além disso conservar o valor das palavras daquela língua da qual se traslada. 
VI.

O que entende Fausto ao falar de tradução palavra por palavra? A tradução palavra por palavra na concepçáo faustina, ou ut interpres segundo Cícero, deve, quando for oportuno, conservar inclusive a ordem das palavras, contudo, sem transpô-las. Traduzir $u t$ interpres também tem seus limites. Sua prática levada aos extremos serve apenas para fins de comparação entre os sistemas lingǘsticos implicados (\$130). A mera transposição das palavras de uma língua a outra seria absurda e não respeitaria a proprietas de nenhuma das línguas, porque ogni lingua ha li soi modi, le sue vaghezze, i soi splendori, li quali non corrispondono a l'altre (\$122), "cada língua tem seus modos, suas belezas, e seus esplendores, os quais não correspondem às outras" Oculto apresenta alguns exemplos de gramática comparada para fazer Inquieto compreender que a tradução palavra por palavra não deve ser entendida literalmente, sob perigo de infringir as regras da morfologia e sintaxe da língua de chegada (as regras do número, gênero, caso, ordem das palavras, uso das conjunçóes, etc.) (\$\$ 123-130). A tradução literal sem limites tira a beleza e a graça da proprietas da língua original, porque o simples cômputo das palavras uma por uma apenas para preencher espaços generarebbe goffezza e perturbaria di maniera $i$ sensi che non sintenderebbono $(\$ 128)$, "produziria torpeza e perturbaria de tal maneira os sentidos que não se entenderiam" Quando não é possível conservar a ordem nem o mesmo número de palavras, deve-se traduzir o sentido por outras locuçôes correspondentes, escreveria Fausto no prefácio a sua tradução do Apoftemmi, em 1546 (Guthmüller 1991: 41). Do tradutor-interpres se exige que se mantenha tâo próximo do estilo do original quanto lhe permitam as estruturas da língua de chegada. Traduzir ut interpres é o verdadeiro modo de traduzir, cioè di stare ne le parole se esser pù̀ e isprimere il senso (\$ 149), "isto é, permanecer nas palavras o quanto for possível e expressar o sentido", no mesmo estilo do modelo. Este modo de traduzir é muito mais difícil

perché presuppone tre gran cognitioni: una del senso, l'altra de la lingua ne la quale si traduce, la terza de la lingua da la quale si traduce. (Fausto da Longiano 1991: \$151)

porque pressupōe três grandes conhecimentos: um do sentido; o outro da língua na qual se traduz; o terceiro, da lingua da qual se traduz. 
VII.

Depois de ter tratado da tradução em geral, Fausto começa a apresentar consideraçōes particulares. Seguindo o modelo da retórica clássica (materia artis, partes artis, elocutio), divide os elementos das composiçōes a traduzir em matéria, distribuição e elocução (soggetto, distributione, elocutione) (\$\$159-179).

A matéria refere-se ao conhecimento do assunto a traduzir. Considerado enquanto geral e particular, é no particular (período, membros e incisos) que o tradutor pode encontrar dificuldades. São muitas as causas da obscuridade dos pensamentos. A distribuiçāo refere-se ou à disposiçāo da matéria, e nisto não deve o tradutor sair da ordem estabelecida, ou à colocação das palavras, e porque cada língua tem suoi modi di dire, deve seguir o gênio (vaghezza) da língua na qual traduz. O ponto mais importante diz respeito ao amplo campo da elocuçāo, que considera as palavras isoladas e agrupadas (uerba singula et coniuncta).

Trata primeiramente das uerba singula. Renunciando às usuais distinçōes da retórica clássica, Fausto busca uma classificação mais relevante para a questão da traduçāo - Inutili non sono queste distintioni, ma per la tradottione è necessario distinguerle in altra maniera $(\$ 167)$, "não são inúteis estas distinçōes, mas para a tradução é necessário distingui-las de outra maneira" -, porém os critérios estabelecidos nāo são muito esclarecedores: as palavras podem ser (1) comuni, palavras latinas que sobrevivem no italiano (amor-amore, studium-studio, voluntas-voluntà, animus-animo...) ( $\$ 167)$; (2) de scontro ("encontro"), palavras latinas que, embora encontrando correspondente no italiano, são de raízes diferentes (ortus-nascimento, interitus-morte...) (\$168); (3) palavras que não têm o scontro e que devem ser empregadas como se encontram (cliens-cliente, clientela-clientela, proquaestor-proquestor...) (\$ 168) - são palavras que expressam fenômenos culturais e sociais específicos da Antigüidade sem correspondência na Itália cinquecentista, e seu emprego é necessário para náo produzir uma tradução anacrônica; (4) antiche, as que mantêm sua majestade (conhecidas, senatus-senato, respublica-republica, ou desconhecidas, teruntium, lessus ...) (\$ 169); (5) di piena significatione em sua língua original, é necessário suportá-las, ainda que duras e ásperas na língua de chegada; com o uso 
se tornam doces e macias (é o caso de palavras gregas em latim, que o italiano recebeu já sem problemas, como os nomes de ciências, grammatica, retorica, dialettica, aritmetica, geometria, astrologia, musica, teologia, fllosofia, metafisica..., ou nomes de enfermidades, para as quais o italiano quis servir-se de vocábulos antes gregos que latinos, como bydropisia) ( $\$ \$ 170-171)$.

As uerba coniuncta são a união das palavras entre si (nomes, verbos, advérbios, adjetivos...). Quando unidos, os nomes e os verbos produzem locuçóes idiomáticas, também chamadas modo, maneira, figura, forma de dizer. As locuçōes dividemse em próprias e trasladadas ou figuradas. Lo tradottore in questo ha da stare molto avertito ( $\$ 172)$, "o tradutor deve estar muito atento a isto"

As palavras que não têm correspondente (scontro) e não podem ser mantidas em sua língua originária, por ser de difícil compreensáo, podem ser traduzidas por meio de circunlocuçóes ( $\$ \$ 174-179$ ). Diante da aparição de uma coisa nova, há duas opiniōes comuns e divergentes: criar palavras novas ou não. Muitos consentem na criaçáo de neologismos ( $\$ \$ 180$-199) ao tratar-se de línguas vivas, como o italiano, mas não nas línguas mortas, como a "hebraica, a grega e a latina" $(\$ 180)^{3}$ Para Fausto, a criação é justificada para todas as línguas, uma vez que se trate de representar uma coisa nova que ainda não tem nome. E por meio da analogia e com o uso do ouvido, podem-se criar palavras novas:

è lecito, e sempre serà lecito, formare voci nuove per analogia, pur che non sieno talmente aspre che non le abhorriscono l'orechie. (Fausto da Longiano 1991: $\$ 193$ )

é lícito e sempre o será formar palavras novas por analogia, porém que nảo sejam talmente ásperas que irritem os ouvidos.

O neologismo se efetua de quatro modos: por similitudine (analogia), imitatione (decalque), inflessione (empréstimo com adaptação morfológica à língua de

3. Fausto se refere às línguas clássicas como mortas. Guthmüller lembra, em nota da ediçáo crírica do texto faustino (1991: 97n.111), que o conceito de lingua morta e lingua viva aparece por primeira vez no Dialogo delle lingue, 1542, de Sperone Speroni. 
chegada) e compositione (palavras compostas) (\$199)4. Apenas não é lícito inovar na elocução ( $\$ 200$ ) das línguas mortas, mas deve-se seguir a propriedade do falar dos antigos, que se encontra nas obras que deixaram. Em seguida ( $\$ 201)$, Fausto alude à consideração devida aos proverbi, mas não trata deles. Guthmüller, em seu ensaio, recorre ao prefácio faustino de 1544 às Epistole dette le familiari, em que o tradutor se revela

cosciente del fatto che in molti casi esistono degli equivalenti moderni [ai proverbi antichi], ma egli desidera tuttavia recuperare in italiano i proverbi antichi, invece di sacrificarli (Guthmüller 1991: 46).

Embora sem fazer alusão direta à questão da inferioridade das novas línguas romances ante a copia et abundantia de palavras das línguas clássicas - o que era considerado um dos principais critérios para avaliação da riqueza de uma língua -, Fausto contesta dita posição afirmando que ogni volta che una lingua possa isprimere $i$ soi concetti, contentar si dee de la richezza ( $\$ 187)$, "toda vez que uma língua possa expressar seus conceitos, deve se contentar de sua riqueza". Após analisar as línguas grega, latina e hebraica, Oculto pondera que uma língua pode ser julgada mais rica que outra por dois critérios: pela piegatura, "dobradura" (declinação e conjugação), e pela facoltà pertrattate, "matéria tratada" (o acervo cultural de cada língua) ( $\$ \$ 187-190$ ).

\section{VIII.}

Nas traduções devem-se considerar também outros fatores, como a idade do texto a traduzir, a língua na qual foi escrito, a matéria de que trata, o autor que o produziu e o público destinado $(\$ 201)$, aconselha Fausto, sem deter-se, porém, em explicaçōes a respeito. $\mathrm{Na}$ tradução de um texto antigo, por exemplo, o erudito italiano aconselha conservar o universo cultural da língua de partida: o latino $m e$ Hercle passa ao italiano como me Hercole $(\$ 202)$.

4. B. Guthmüller reconhece a fonte deste pensamento faustino sobre as quatro formas de criar neologismos no preceito de Cícero em Partitiones onatoriae $(V, 16)$ : ... aut similitudine aut imitatione aut inflexione aut adiunctione verborum. 
Fausto também aborda a questáo da tipologia de textos. Apresenta a classificação corrente dos tipos de textos a traduzir: os que tratam das coisas (artes e ciências) e os que tratam das palavras (retóricos, poéticos, dissertativos), ou seja, uns que dáo maior importância ao conteúdo e outros ao estilo ( $\$ \$ 157-158$ ), mas reformula a questáo propondo uma divisāo válida para todos os tipos de textos: saggetto, distributione, elocutione, quer dizer, independentemente do gênero de texto, em toda tradução devem-se considerar estes três elementos: matéria, ordenaçáo e elocuçáo. Nos textos técnicos e científicos, é necessário utilizar seus termos técnicos para o entendimento, apesar da possibilidade de criar uma traduçáo algo dura. $O$ exemplo foi dado por Cícero em sua tradução - hoje perdida - do Econômico de Xenofonte ( $\$ 203)$. No entanto, isso não vale para as traduçóes de história, epístolas e discursos. Diferindo da maioria de seus contemporâneos, Fausto mantém a tese de que causa maggiore difficultà tradurre l'oratione che altra compositione (\$204), "maior dificuldade traduzir um discurso que outra composiçāo"s. As principais dificuldades da tradução de discursos - destinados mais a serem declamados que lidos - consistem na compositione (eufonia), degnitade (figuras retóricas) e numero (ritmo), ou seja, elementos que tratam principalmente da elocutio do texto ( $\$ \$ 205-272)$.

A compositione (iunctura) resulta da uniāo de vogais e consonantes. Como disse Cícero no Orator (XLIV, 149 ss.), e Fausto o cita, Diffcilius est scribere soluta oratione quam versu, "é mais difícil escrever em prosa que em verso", porque ao poeta se concede mais liberdade. $\mathrm{Na}$ tradução em prosa é mais difícil manter o mesmo número de palavras "gravi, sonanti e piene" do original (\$\$ 206-214).

A degnitade (fgurae) é também chamada "exornação, forma, figura, esquema, ornamento, luz, cor" ( $\$ 215)$. Sua função é ilustrar o discurso e fazê-lo brilhar. Refere-se sobretudo às figuras de palavras, "che si fondano sul rapporto di somiglianza formale esistente tra determinati vocaboli" (Guthmüller 1991: 47). Muitas vezes na tradução ou não se pode reproduzir a degnitade, ou se perde sua beleza.

5. Segundo Gurhmüller, quando escreveu o Dialogo, Fausto estava traduzindo discursos de Cicero (1991: 102). 
O numero (numerus) impede que o discurso se torne débil e coxo ( $\$ 218)$. Nas línguas latina e grega, o ritmo é dado pelas sillabas longas e breves; nas línguas neolatinas corresponde aos acentos agudos e graves. Porém, porque são distintos os sistemas, deve-se admitir que a tradução plena do ritmo latino e grego nas línguas romances é impossivel. Isso não significa para Fausto que o italiano seja inferior às línguas clássicas, mas que é diferente. Ao traduzir, portanto, deve-se favorecer aos dois tipos de ritmo e atender à utilidade comum $(\$ 273)$. Ao tratar do numero, Fausto produz uma interminável discussão especializada sobre os diversos metros antigos, suas definiçōes e funçōes, revelando uma vez mais sua grande erudiçãa ${ }^{6}$, como o fizera ao dissertar sobre as forme e figure, porém pouco frutífera para a questão da tradução. No entanto, pode-se comparar a longa exposição deste assunto, conforme lembra Guthmüller, com a importância dedicada a ele também por Cícero no Orator, que é a principal fonte de Fausto (1991: 47).

IX.

A última parte do tratado faustino apresenta uma comparaçāo entre as duas traduçōes que foram objeto de discussão e pretexto para as reflexōes de Fausto. Sem nomear nenhuma vez os tradutores em questão, os autores podem ser reconhecidos mediante a análise de seus respectivos títulos: Epistole di $M$. T. Cicerone dette le familiari, recate in italiano (\$274), de Fausto da Longiano, e Le epistole famigliari, tradotte segondo $i$ veri sensi de l'autore e con figure proprie de la lingua volgare $(\$ 292$ ss.), de Guido Loglio. O exemplo positivo é representado pela traduçáo de Fausto e o negativo pela de Loglio. Oculto critica Loglio já pelo título empregado na traduçáo ( $\$ \$ 292-298)$, pela dedicatória e sua concepçáo de tradução (\$\$ 299-332) e pela própria tradução ( $\$ 333-342)$, a qual pecchi in materia e in forma $(\$ 346)$ "peca na matéria e na forma", ou seja, o tradutor traiu a forma lingüístico-literária e com isso o sentido do original. Para o tratadista, Loglio não entendeu o pensamento de Cícero (\$ 299) e náo fez traduçáo, mas ilustração $(\$ 315)$.

6. Ao longo de seu tratado, Fausto faz referências a quase 80 obras e cerca de 40 autores. 
Non ha tradotto come interprete, né come oratore con le medesime sentenze e forme e figure, non ha servato il genere né la vertù de le parole, ha rotto il nervo, ha guasto la compositione, senza alcuna osservanza di numero. (Fausto da Longiano 1991: $\$ 346$ )

Năo traduziu como intérprete nem como orador com as mesmas sentenças e formas e figuras, não conservou o gênero nem o valor das palavras, rompeu o nervo, desgastou a composiçáo, sem nenhuma observância da cadência rítmica.

Uma mostra da concepçáo tradutiva de Fausto na prática é oferecida pelas oraçōes iniciais da traduçáo do texto ciceroniano, analisadas no Dialogo ( $\$ \$ 334-346$ ):

Ego omni officio ac potius pietate erga te caeteris satisfacio omnibus, mihi ipse nunquam satisfacio. Tanta enim magnitudo est tuorum erga me meritorum, ut, quoniam tu, nisi perfecta re, de me non conquiesti, ego, quia non idem in tua causa efficio, vitam mihi esse acerbam putem. (Cícero, Epistolae ad familiares)

Io con ogni ufficio, anzi pietà ver te sodisfaccio a tutti, ma non sodisfaccio a me stesso giamai, perché tanta è la grandezza de' tuoi meriti verso me, che, perché tu, se non effettuata la coisa, di me non posasti, perché il medesimo ne la causa tua non faccio, riputo essermi la vita noiosa. (Fausto, Epistole dette le familiari)

Parmi esser certo che turti quelli che veggono con quanto studio e affanno mi affatico per te, grande estimano la gratitudine mia; ma io non posso già tanto affaticarmi che l'animo mio ne rimanga contento, percioché è tanta la grandezza de' toi meriti verso di me, che, non potendo io le cose tue a quel fine condurre, che tu hai condotte le mie, quasi che m'è discara la vita. (Loglio, Le epistole famigliari)

\section{A teoria faustina de tradução}

A relação de Fausto com a gramática e retórica clássicas é patente ao longo de todo o tratado, como pudemos perceber durante a análise do conteúdo, e um estudo sobre este ponto já foi apresentado em outro momento. Importa aqui determo-nos no pensamento central de sua concepção de tradução. $O$ tratado faustino é, ao fim e ao cabo, a defesa da concepçáo tradutora de seu autor, fundada sobre uma releitura do clássico texto ciceroniano De optimo genere oratorum. Fausto 
entende a correta tradução como reprodução "total" do original, conservando a mesma ordem dos pensamentos, com as mesmas formas e figuras e, quando possível; com o mesmo número de palavras do texto modelo, acomodando as palavras ao gênio da língua de chegada, mantendo os mesmos valores presentes na língua de partida, e com o correspondente estilo de seu autor e todo seu sentido. A concepção faustina de sentido - inferida ao longo da pesquisa - é indissolúvel da forma, assim como o são as palavras e as coisas. Uma tradução que não consiga reproduzir a forma como um todo não é capaz de reproduzir o sentido. No entanto, não se deve confundir o preceito de máxima proximidade ao original com uma mera transposição de seus elementos formais. O limite da tradução ut interpres é, pois, o respeito à proprietas da língua de chegada, a qual deve ser explorada em todas suas possibilidades.

A tradução ut interpres "è molto più difficile" que outros tipos "perchè presuppone tre gran cognitioni: una del senso, l'altra de la lingua ne la quale si traduce, la terza de la lingua da la quale si traduce" ( $\$ 151)$. Estes requisitos tornaram-se, desde as reflexōes de Bruni (1420), um lugar-comum nos tratados sobre tradução. O conhecimento do sentido do texto a traduzir abarca, para Fausto, conteúdo e forma, e é possibilitado pelo domínio das línguas envolvidas, tanto em nível gramático como retórico. $\mathrm{O}$ conhecimento do sentido está relacionado ao primeiro dos elementos que constituem cada composição a traduzir, ou seja, a matéria (soggetto) tanto no geral (assunto, arte, ciência), como no particular (propriedades lingüísticas e estilísticas). O segundo dos elementos, a distribuição (dispositio), diz respeito não apenas ao conhecimento do sentido, mas também ao das línguas envolvidas na tradução. A distribuiçãa enquanto disposição da matéria refere-se à ordem dos pensamentos estabelecida pelo autor, que não deve ser alterada pelo tradutor; porém, enquanto colocaçáo das palavras, apela à peritia linguarum (o domínio das línguas) do tradutor, para que respeite o gênio da língua de chegada.

Entre todos os princípios gramático-retóricos envolvidos no processo da tradução ut interpres, aquele que sem dúvida ocupa o lugar central é o da elocutio, o terceiro elemento. Fausto tem isso muito claro, e o dá a conhecer, que o tradutor é um 
grande artesáo da palavra - é um escritor -, podendo produzir na língua em que traduz distintos tipos de oratio, que em linhas gerais se apresentam sob dois aspectos - como o sistematizará Schleiermacher no século XIX -, a saber, o que leva o leitor ao original ou o que traz o original ao leitor. $O$ primeiro pretende maior fidelidade histórica e lingüístico-estilística ante o original; o segundo tenta uma atualizaçáo histórica e uma adaptação linguíístico-estilística à estética vigente. Comum aos dois é o respeito à língua de chegada, porque uma traduçáo - como cada texto - só tem sentido se é compreensível ao leitor. Para Fausto, a correta tradução é a que leva o leitor ao original, nomeando ao outro tipo "ilustração" e nāo tradução.

Segundo o tratadista italiano, uma tradução pode efetuar-se sob três formas: ut orator, ut interpres e por "transposiçāo" dos elementos formais. Esta última alternativa fica descartada porque, geralmente, tem apenas um valor didático de conhecimento dos sistemas lingüísticos das línguas envolvidas e é quase sempre obscura. A transmissão da mensagem passa pela literariedade do texto. Das outras duas opçóes, vimos que Fausto defende a tradução ut interpres, porque, além dos valores presentes na $u t$ orator, se impóe a tarefa de fixar-se nas palavras até o ponto de computá-las.

A tradução ut interpres, portanto, valorizará de forma especial as palavras, seja enquanto uerba singula, seja como uerba coniuncta, em nível gramatical e em nível retórico. A tradução deve aproximar-se o mais possível do original e as palavras que já em sua forma evocam o original têm uma importância particular. Este pensamento justifica a classificação faustina das uerba singula: na tradução deve-se empregar as palavras comuni (as palavras latinas que sobrevivem em italiano), depois, as palavras que têm um correspondente, ainda que de raízes diferentes. Fausto não admite o anacronismo na tradução; por isso, as palavras que expressam fenômenos culturais e sociais de outras épocas e sem correspondentes na atualidade devem ser mantidas no original. Há ainda palavras di piena significatione que devem ser conservadas apesar de sua dureza. Quando estes recursos das uerba singula resultam impotentes na tradução, pode-se recorrer a procedimentos como circunlocuçōes e neologismos. Sobre as uerba coniuncta, Fausto apenas menciona as locuçóes idiomáticas e os provérbios, mas adverte o tradutor para que tenha cuidado. 
A tradução ut interpres, como já mencionamos, não há de cuidar unicamente do aspecto semântico, morfológico e sintático das palavras - pertencentes ao nível gramatical -, ainda que com isso pudesse reproduzir, parcialmente, o sentido, a ordem dos pensamentos, as mesmas formas e número de palavras acomodadas à língua de chegada. Deve também tratar de refletir as mesmas figuras, os valores das palavras e o estilo original - isto é, situar-se no nível retórico -, requisitos que, unidos aos anteriores, podem ser cumpridos pelo ornatus retórico, possibilitando com isso a reprodução do sentido global. "Il vero modo de tradurre è questo, cioè di stare ne le parole se esser può e isprimere il senso" ( $\$ 149)$. As maiores dificuldades na tradução, assinalou Fausto, são de ordem retórico-fônico: compositione (iunctura), degnitade (figurae), e numero (numerus). As palavras devem "servare la vertù, la forza e 'l valore" ( $\$ 120)$ que luzem no original, devem reproduzir, na medida do possível, seus aspectos e permanecer "significanti, sonore, gravi, pieni e numerose" (\$113).

ABSTRACT: Dialogo del modo de lo tradurre, 1556, di Sebastiano Fausto da Longiano è il primo trattato indipendente sulla traduzione scritto in italiano ed ̀̀ uno dei più signiffcativi del Rinascimento europeo. In esso, oltre alle principali posizioni sostenute nei dibattiti sulla traduzione del periodo, si trovano anche $i$ precetti che costituiscono la grande linea di pensiero che caratterizzd la riflessione sulla traduzione rinascimentale chiamata "teoria retorica elocutiva della traduzione": il codice che plasma il concetto di linguaggio nel Rinascimento e, di conseguenza, il concetto di traduzione, a quello della retorica della elocutio. PAROLE CHIAVE: teoria della traduzione; Rinascimento; retorica; Fausto da Longiano.

Bibliografia citada

BRUNI ARETINO, Leonardo, 1928, "De interpretatione recta", in Hans Baron (ed.), Humanistischphilosophische Schriften, Leipzig, Teubner, pp. 81-96.

1996, "De interpretatione recta/Sobre la correcta traducción", in F. Lafarga (ed.), El discurso sobre la traducción en la historia. Antologia bilingüe, Barcelona, EUB, pp. 78-109. Trad. de Alicia Cortés. 
BRUNI ARETINO, Leonardo, 1996, "De interpretatione recta/Sulla perfetta traduzione”, in Opere letterarie e politiche di Leonardo Bruni, Turim, Unione, pp. 150-193.

CfCERO, Marco Tulio, 1948, Tusculanes, Barcelona, Fundació Bernat Metge. Trad. de Eduard Valentl.

1971, Tusculan Disputations, E. H. Warmington (ed.), Londres-Cambridge, HeinemannHarvard University. Trad. de J. E. King.

1967, Orator/El orador, Barcelona, Ed. Alma Mater. Trad. de Antonio Tovar \& Aurelio R Bujaldón.

1978, L'orateur; Du meilleur genre d'orateurs, Paris, Les Belles Lettres. Trad. de Albert Yon. 1996, "De optimo genere oratorum/Sobre el mejor género de oradores", in F Lafarga (ed.), El discurso sobre la traducción en la historia. Antologia bilingüe, Barcelona, EUB, pp. 32-44. Trad. de José Ignacio García Armendáriz.

FAUSTO DA LONGIANO, Sebastiano, 1991, "Del modo de lo tradurre d'una in altra lingua secondo le regole mostrate da Cicerone', in Quaderni Veneti, 12, pp. 57-132.

FOLENA, Gianfranco, 1991, Volgarizzare e tradurre, Turim, Unione Tipografico-Ed. Torinense. GUTHMULLLER, Bodo, 1991, "Fausto da Longiano e il problema del tradurre", in Quaderni Veneti, 12. Trad. de Rosamaria Brandt \& Nicoletta Negri. 1998, "Die Ubersetzung in der italienischen Renaissance", in Bodo Guthmüller (ed.), Latein und Nationalsprachen in der Renaissance, Wiesbaden, Harrassowitz, pp. 9-30.

LAUSBERG, Heinrich, 1999, Manual de retórica literaria - fundamentos de una ciencia de la literatura, 3 vols, Madri, Gredos. Trad. de José Pérez Riesco.

MOUNIN, Georges, 1965, Teoria e storia della traduzione, Turim, Einaudi.

NORTON, Glyn P., 1984, The ideology and language of translation in Renaissance France and their bumanist antecedents, Genebra, Droz.

RENER, Frederick M., 1989, Interpretatio - Language and translation from Cicero to Tytler, Amsterdam/Atlanta, Rodopi. 